\title{
Emotional Intelligence and Occupational Stress among Filipino Teachers
}

\author{
Alberto D. Yazon, Karen Ang-Manaig* \\ College of Teacher Education, Laguna State Polytechnic University, Philippines
}

Received August 20, 2019; Revised October 7, 2019; Accepted October 16, 2019

Copyright $(2019$ by authors, all rights reserved. Authors agree that this article remains permanently open access under the terms of the Creative Commons Attribution License 4.0 International License

\begin{abstract}
This study describes the emotional intelligence and occupational stress among Filipino teachers through descriptive - correlational analysis. Inferential statistics are used to establish a possible relationship between emotional intelligence and occupational stress. The respondents of the study were 797 Filipino teachers who voluntarily participated in an online survey using Google form. The Ganos Emotional Intelligence Inventory was adopted to assess the Emotional Intelligence of the respondents, while an adopted version of the Teacher Stress Inventory (TSI) was used to measure the occupational stress of respondents. The demographic characteristics of the respondents were described and analyzed using frequency count and percentage. Mean was used to measure emotional intelligence level and the strength of occupational stress among the respondents. Furthermore, Pearson $r$ was utilized to test the significant relationship between the main variables of the study. It was found that there is an inverse and high significant relationship between respondent's emotional intelligence and occupational stress dimensions, hence the null hypothesis is rejected. This means that to overcome stress, teachers should have established a strong emotion and positive mindset.
\end{abstract}

Keywords Emotional Intelligence, Occupational Stress, Teachers

\section{Introduction}

Emotional intelligence (EI) is "an array of non-cognitive capabilities, competencies and skills that influence one's ability to succeed in coping with environmental demands and pressures”. It consists of a learned set of competencies that determine how we interact with people. According to Goleman (1995) as cited by Singh (2015), “emotional intelligence is the ability to motivate oneself and persist in the face of frustrations; to control impulse and delay gratification, to regulate one's moods and keep distress from swamping the ability to think; to empathize and hope”.

Further, Schmutz (2017) mentioned that "Emotional Intelligence is a fairly new construct of intelligence, receiving relevance and acknowledgment with the work of scholars” such as Baron (1997), Mayer, Salovey, and Caruso (1995), and Goleman (1995). "Emotional intelligence has been shown to be more directly responsible for job success than cognitive intelligence (Goleman, 1995; Stein \& Book 2011), otherwise known as IQ (Weschler, 1939)”. Emotional intelligence, as defined by Multi-Health Systems (2016a), the producer of the emotional quotient inventory tool EQ-i 2.0, is "a set of emotional and social skills that influence the way we perceive and express ourselves, develop and maintain social relationships, cope with challenges, and use emotional information in an effective and meaningful way."

Palmer, Stough, Harmer and Gignac (2019) defined "Emotional Intelligence as Emotional Intelligence (EI) or emotional quotient (EQ) as a set of skills that help us better perceive, understand and manage emotions in ourselves and in others". Collectively they help us make intelligent responses to, and use of, emotions. "These skills are as important as your intellect (IQ) in determining success in work and in life. Everyone, no matter what job function, has interactions with other people. Your capacity to understand your emotions, to be aware of them and how they impact the way you behave and relate to others, will improve your 'people' skills and help you ultimately be more satisfied and successful”.

Goleman (as cited by Sommers, 2016) described "the impact of emotional intelligence (EI) in the school and classroom on learners' development”. Within the classroom setting, when "a teacher acts without EI, this can cause a student and/or students to feel emotionally "hijacked," negatively impacting their ability to learn" (Sommers, 2016 as cited by Schumtz, 2017). 
Tajudin, et al (2014) found that "Emotional Intelligence correlates with teacher competence wherein high level of emotional intelligence has significant correlation with high level of capability". Their research involved 169 high school teachers in the province of Tuscany, Italy. Further, the study revealed that emotional intelligence is associated with higher self-efficacy, teacher with higher ability to manage the classroom, students' motivation and appropriate teaching strategies.

Meanwhile, "occupational stress pertains to the physical, mental, and emotional reactions of employees who perceive that their work demands exceed their abilities and/or their resources (e.g. time, access to help/support) to do the work" (Work Cover State of Queensland, 2019). Thus, significant health and safety issues for workers were caused by occupational stress.

The World Health Organization (2019) claimed that "a healthy job is likely to be one where the pressures on employees are appropriate in relation to their abilities and resources, to the amount of control they have over their work, and to the support they receive from people who matter to them. As health is not merely the absence of disease or infirmity but a positive state of complete physical, mental and social well-being (WHO, 1986), a healthy working environment is one in which there is not only an absence of harmful conditions but an abundance of health-promoting ones”. Quick and Demetria (2016) stated that "occupational stress is a known health risk for a range of psychological, behavioral, and medical disorders and diseases. They also described stress as directly linked to the top leading causes of death in the world, such as cardiovascular disease being the prominent cause for both men and women”.

Jain and Batra (2015) cited Beehr and Newman (1978) that "occupational stress in the workplace causes anxiety like walking dread in the office every morning and then make them worry about their jobs at night. It has become more globalized and has the tendency to affect all workers irrespective of the job profile or category, the only difference being the intensity levels. Stress as a situation which forces a person to deviate from its routine functioning due to change in psychological or physiological condition” (Beehr \& Newman, 1978).

"One of the most stressful professions is teaching for a variety reasons based upon the findings of Johnson et al. (2005); Roeser et al.,(2013) as cited by Hendres, Curelaru, Arhiri, Gherman and Diac (2014). One of the main theories that attempts to explain the high levels of stress associated with teaching focuses on the high levels of social and emotional personal resources that teachers are supposed to invest when working with large numbers of children and/or adolescents at the same time (Schutz \& Zembylas, 2009; Zapf, 2002)". Other theories argue that the activity of teaching requires great decisional flexibility and creativity due to the ever-changing nature of the work environment (Roeser et al., 2012). Basically, a teacher is supposed to come up with hundreds of ad-hoc decisions every day, which demands a high tolerance for uncertainty and great and consistent abilities of attention focusing.

The abovementioned realities prompted the researchers to examine the emotional intelligence and occupational stress among Filipino teachers using a descriptive-correlational research design. Likewise, a relationship between those two constructs was determined to come up with teacher development plan designed to strengthen the emotional intelligence of teachers and lessen their occupational stress.

\subsection{Purpose of the Study}

The purpose of this explorative study was to describe aspects of emotional intelligence and occupational stress amongst Filipino teachers through a descriptive correlational analysis, and through inferential statistics, to establish a possible relationship between emotional intelligence and occupational stress.

\subsection{Research Questions}

1. What is the demographic characteristics of the respondents in terms of sex, number of years in teaching, year level handled, type of school, and highest educational attainment?

2. What is the level of emotional intelligence of the respondents?

3. What is the level of occupational stress of the respondents?

4. Is there a significant relationship between the emotional intelligence and occupational stress of the respondents?

\section{Methodology}

The study employed descriptive-correlational research design since it investigates the relationships among two or more variables (Calmorin and Calmorin, 2010). This design was appropriate to use since the study involves describing, analyzing, interpreting the present nature, and the relationship between emotional intelligence and occupational stress.

The respondents of the study were the 797 Filipino teachers who voluntarily participated in an online survey using Google form.

The Ganos Emotional Intelligence Inventory of Palmer, Harmer, and Gignac (2009) was adopted to assess the EI of the respondents. It is a 14-item scale which according to the proponents measured a simple rather than complex model, was able to be completed in less than 15 minutes, has high "workplace face validity, and generated scores that were meaningfully related to the organizational and role specific outcomes. It has an internal consistency reliability of $\alpha=0.87$. The EI inventory is scored on a 
5-point Likert scale: 1 = Almost Never, 2 = Seldom, 3 = Sometimes, $4=$ Usually, and $5=$ Almost Always. The scale contains eight (8) true keyed items and six (6) false keyed items. The latter were reverse coded prior to calculating the Total EI score.

Meanwhile, the respondent's occupational stress was determined through an adopted Teacher Stress Inventory (TSI) of Fimian (1988). It is composed of 49 stress-related items with ten (10) subscales or factors such as professional investment, behavioral manifestations, time management, discipline and motivation, emotional manifestations, work-related stress, gastronomic manifestations, cardiovascular manifestations, fatigue manifestations, and professional distress. Each subscale is composed of three to eight items which takes 15 minutes to complete. TSI has a reliability index $\alpha=0.93$. It is also a - point Likert scale: 1 = no strength, not noticeable, 2 = mild strength, barely noticeable; 3 = medium strength, moderately noticeable, 4 = great strength, very noticeable, and 5 = major strength, extremely noticeable. Each subscale on the TSI is scored one at a time. The total stress score was computed based on the average mean score of the ten subscales.
The demographic characteristics of the respondents were described and analyzed using frequency count and percentage. Mean was used to measure emotional intelligence level and the strength of occupational stress among the respondents. Furthermore, Pearson $r$ was utilized to test the significant relationship between the main variables of the study.

\section{Results and Discussions}

Table 1 shows the demographic characteristics of the respondents in terms of sex, length of teaching experience, type of school, year level handled, and highest educational attainment

As shown in Table 1, majority (88.2\%) of the respondents are female which consistently justify that the teaching profession is a female - dominant profession. Most (57.8\%) of them are teaching for almost 10 years now. A great majority (97.9\%) are tenured in public schools which connote a secured and well-compensated job than those from private institutions. More than half (58.2\%) of the respondents are bachelor's degree and still need to pursue further studies.

Table 1. Demographic characteristics of the respondents in terms of sex, length of teaching experience, type of school, year level handled, and highest educational attainment

\begin{tabular}{|c|c|c|}
\hline Demographic Characteristic & Frequencies & Frequency Percentages \\
\hline \multicolumn{3}{|l|}{ Sex } \\
\hline Male & 94 & 11.8 \\
\hline Female & 703 & 88.2 \\
\hline \multicolumn{3}{|l|}{ Length of Teaching Experience } \\
\hline $1-10$ years & 461 & 57.8 \\
\hline $11-20$ years & 226 & 28.4 \\
\hline $21-30$ years & 97 & 12.2 \\
\hline$>30$ years & 13 & 1.6 \\
\hline \multicolumn{3}{|l|}{ Type of School } \\
\hline Private & 17 & 2.1 \\
\hline Public & 780 & 97.9 \\
\hline \multicolumn{3}{|l|}{ Year Level Handled } \\
\hline Tertiary & 575 & 72.1 \\
\hline Senior High School & 192 & 24.1 \\
\hline Junior High School & 17 & 2.1 \\
\hline Elementary & 13 & 1.6 \\
\hline \multicolumn{3}{|l|}{ Highest Educational Attainment } \\
\hline Doctorate Degree & 25 & 3.1 \\
\hline Master's Degree & 308 & 38.6 \\
\hline Bachelor's Degree & 464 & 58.2 \\
\hline Total (N) & 797 & 100.00 \\
\hline
\end{tabular}


Table 2. Emotional Intelligence (EI) level of the respondents

\begin{tabular}{|c|c|c|c|c|}
\hline Indicative Statement & Mean & $\begin{array}{l}\text { Std. } \\
\text { Dev. }\end{array}$ & DI & Level \\
\hline I appropriately communicate decisions to stakeholders. & 3.66 & 0.87 & $\mathrm{U}$ & High \\
\hline I fail to recognize how my feelings drive my behavior at work. (R) & 2.37 & 0.91 & Se & Low \\
\hline When upset at work, I still think clearly. & 3.75 & 0.94 & $\mathrm{U}$ & High \\
\hline I fail to handle stressful situations at work effectively. (R) & 2.54 & 1.00 & So & Moderate \\
\hline I understand the things that make people feel optimistic at work. & 3.80 & 0.91 & $\mathrm{U}$ & High \\
\hline I fail to keep calm in difficult situations at work. (R) & 2.50 & 1.04 & So & Moderate \\
\hline I am effective in helping others feel positive at work. & 3.84 & 0.88 & $\mathrm{U}$ & High \\
\hline I find it difficult to identify the things that motivate people at work. (R) & 2.35 & 0.95 & Se & Low \\
\hline I consider the way others may react to decisions when communicating them. & 3.68 & 0.90 & $\mathrm{U}$ & High \\
\hline I have trouble finding the right words to express how I feel at work. (R) & 2.42 & 1.00 & Se & Low \\
\hline When I get frustrated with something at work I discuss my frustration appropriately. & 3.33 & 0.95 & So & Moderate \\
\hline I don't know what to do or say when colleagues get upset at work. (R) & 2.46 & 0.91 & Se & Low \\
\hline I am aware of my mood state at work. & 3.79 & 0.92 & $\mathrm{U}$ & High \\
\hline I effectively deal with things that annoy me at work. & 3.53 & 0.89 & $\mathrm{U}$ & High \\
\hline Overall & 3.14 & 0.49 & So & Moderate \\
\hline
\end{tabular}

(R) - Reversely Scored

$\begin{array}{ll}\text { Mean } & \text { Descriptive Interpretation (DI) } \\ 4.50-5.00 & \text { Almost Always (AA) } \\ 3.50-4.49 & \text { Usually (U) } \\ 2.50-3.49 & \text { Sometimes (So) } \\ 1.50-2.49 & \text { Seldom (Se) } \\ 1.00-1.49 & \text { Almost Never (AN) }\end{array}$

Table 2 presents the emotional intelligence (EI) level of the respondents.

Generally, the respondents have a moderate level of emotional intelligence with an overall mean score of 3.14 $(\mathrm{SD}=0.49)$. This means that teachers - respondents possess an average level of accurate appraisal of emotions among themselves and others. They also exhibit appropriate expression and adaptive regulation of their emotions.

As presented in Table 2, the respondents are usually aware of their mood state and they effectively deal with things that annoy them at work. They mostly consider the way others may react to decisions when communicating them. According to them, they are effective in helping others feel positive at work and understand the things that make people feel optimistic. When upset at work, these teachers can still think clearly. If these parameters are considered, the teacher-respondents are considered to have high levels of emotional knowledge and able to demonstrate effective use of that knowledge in the workplace.

However, they admitted that they sometimes fail to
Level

Very High

High

Moderate

Low

Very Low handle stressful situations at work and fail to keep calm in difficult situations. These self-reported assessment may be attributed by voluminous workload among teachers. They are sometimes burdened by a lot of tasks expected of them to perform which triggers mismanagement of their emotions.

Nevertheless, Filipino teachers are characterized to be resilient and patient. No matter how difficult the task may be, they can still find ways to overcome difficult situations. They try to become more positive to achieve better results not only for themselves, but more importantly, for the learners they are nurturing.

Table 3 depicts the occupational stress level of the respondents in terms of professional investment.

As depicted in Table 3, the respondents sometimes notice that their personal opinions are not sufficiently aired with a mean score of $2.65(\mathrm{SD}=1.07)$. With an overall mean score of $2.47(\mathrm{SD}=0.89)$, they barely experience that they lack control over decisions made about classroom/school matters; not emotionally/intellectually stimulated on the job, and lack opportunities for professional improvement. 
Table 3. Occupational Stress (OS) level of the respondents in terms of professional investment

\begin{tabular}{|c|c|c|c|c|}
\hline Indicative Statement & Mean & Std. Dev. & DI & Level \\
\hline My personal opinions are not sufficiently aired. & 2.65 & 1.07 & MeS & MN \\
\hline I lack control over decisions made about classroom/school matters. & 2.46 & 1.02 & MiS & $\mathrm{BN}$ \\
\hline I am not emotionally/intellectually stimulated on the job. & 2.34 & 1.10 & MiS & $\mathrm{BN}$ \\
\hline I lack opportunities for professional improvement. & 2.41 & 1.10 & MiS & $\mathrm{BN}$ \\
\hline Overall & 2.47 & 0.89 & MiS & BN \\
\hline
\end{tabular}

$\begin{array}{lll}\text { Mean } & \text { Descriptive Interpretation (DI) } & \text { Level } \\ 4.50-5.00 & \text { Major Strength (MaS) } & \text { Extremely Noticeable (EN) } \\ 3.50-4.49 & \text { Great Strength (GS) } & \text { Very Noticeable (VN) } \\ 2.50-3.49 & \text { Medium Strength (MeS); } & \text { Moderately Noticeable (MN) } \\ 1.50-2.49 & \text { Mild Strength (MiS) } & \text { Barely Noticeable (BN) } \\ 1.00-1.49 & \text { No Strength (NS) } & \text { Not Noticeable (NN) }\end{array}$

Table 4 presents the occupational stress level of the respondents in terms of time management.

Table 4. Occupational Stress (OS) level of the respondents in terms of time management

\begin{tabular}{|c|c|c|c|c|}
\hline Indicative Statement & Mean & Std. Dev. & DI & Level \\
\hline I easily over-commit myself. & 3.28 & 0.98 & $\mathrm{MeS}$ & MN \\
\hline I become impatient if others do things to slowly. & 2.71 & 1.11 & $\mathrm{MeS}$ & MN \\
\hline I have to try doing more than one thing at a time. & 3.48 & 1.00 & $\mathrm{MeS}$ & MN \\
\hline I have little time to relax/enjoy the time of day. & 3.35 & 1.04 & MeS & MN \\
\hline I think about unrelated matters during conversations. & 2.53 & 1.13 & $\mathrm{MeS}$ & MN \\
\hline I feel uncomfortable wasting time. & 3.39 & 1.20 & $\mathrm{MeS}$ & MN \\
\hline There isn't enough time to get things done. & 3.13 & 1.11 & $\mathrm{MeS}$ & MN \\
\hline I rush in my speech. & 2.60 & 1.03 & MeS & MN \\
\hline Overall & 3.06 & 0.66 & MeS & MN \\
\hline
\end{tabular}

$\begin{array}{lll}\text { Mean } & \text { Descriptive Interpretation (DI) } & \text { Level } \\ 4.50-5.00 & \text { Major Strength (MaS) } & \text { Extremely Noticeable (EN) } \\ 3.50-4.49 & \text { Great Strength (GS) } & \text { Very Noticeable (VN) } \\ 2.50-3.49 & \text { Medium Strength (MeS); } & \text { Moderately Noticeable (MN) } \\ 1.50-2.49 & \text { Mild Strength (MiS) } & \text { Barely Noticeable (BN) } \\ 1.00-1.49 & \text { No Strength (NS) } & \text { Not Noticeable (NN) }\end{array}$

As presented in Table 4, the respondents sometimes try doing more than one thing at a time with the highest mean score of 3.48 (SD =1.00). As a result, they feel uncomfortable wasting time and have a little time to relax/enjoy the time of day. With the lowest mean score of $2.53(\mathrm{SD}=1.13$ ), the respondents think about unrelated matters during conversations. The overall mean score of 3.06 ( $\mathrm{SD}=0.66$ ), it is moderately noticeable that the respondents experience a medium strength of time management as a source of occupational stress.

Table 5 reveals the occupational stress level of the respondents in terms of work-related stressors. 
Table 5. Occupational Stress (OS) level of the respondents in terms of work-related stressors

\begin{tabular}{|c|c|c|c|c|}
\hline Indicative Statement & Mean & $\begin{array}{c}\text { Std. } \\
\text { Dev. }\end{array}$ & DI & Level \\
\hline There is little time to prepare for my lessons/responsibilities. & 3.04 & 1.13 & MeS & MN \\
\hline There is too much work to do. & 3.75 & 1.08 & $\mathrm{GS}$ & $\mathrm{VN}$ \\
\hline The pace of the school day is too fast. & 3.40 & 1.00 & $\mathrm{MeS}$ & $\mathrm{MN}$ \\
\hline My caseload/class is too big. & 2.86 & 1.15 & $\mathrm{MeS}$ & $\mathrm{MN}$ \\
\hline My personal priorities are being short-changed due to time demands. & 3.30 & 1.05 & $\mathrm{MeS}$ & $\mathrm{MN}$ \\
\hline There is too much administrative paperwork in my job. & 3.46 & 1.11 & $\mathrm{MeS}$ & $\mathrm{MN}$ \\
\hline Overall & $\mathbf{3 . 3 0}$ & $\mathbf{0 . 8 2}$ & $\mathbf{M e S}$ & MN \\
\hline
\end{tabular}

$\begin{array}{lll}\text { Mean } & \text { Descriptive Interpretation (DI) } & \text { Level } \\ 4.50-5.00 & \text { Major Strength (MaS) } & \text { Extremely Noticeable (EN) } \\ 3.50-4.49 & \text { Great Strength (GS) } & \text { Very Noticeable (VN) } \\ 2.50-3.49 & \text { Medium Strength (MeS); } & \text { Moderately Noticeable (MN) } \\ 1.50-2.49 & \text { Mild Strength (MiS) } & \text { Barely Noticeable (BN) } \\ 1.00-1.49 & \text { No Strength (NS) } & \text { Not Noticeable (NN) }\end{array}$

As revealed in Table 5, the respondents greatly feel that there is too much work to do (mean $=3.75$, SD $=1.08$ ). Similarly, they feel that there is too much administrative paperwork in their job and sometimes their personal priorities are being short-changed due to time demands with a mean score of 3.46 and 3.30 respectively. Generally, it is moderately noticeable that work-related stressors are evident among the respondents as they perform their duties and responsibilities as teachers of today's generation.

Table 6 illustrates the occupational stress level of the respondents in terms of professional distress.

Table 6. Occupational Stress (OS) level of the respondents in terms of professional distress

\begin{tabular}{|c|c|c|c|c|}
\hline Indicative Statement & Mean & Std. Dev. & DI & Level \\
\hline I lack promotion and/or advancement opportunities. & 2.76 & 1.09 & $\mathrm{MeS}$ & MN \\
\hline I am not progressing my job as rapidly as I would like. & 2.67 & 1.07 & $\mathrm{MeS}$ & $\mathrm{MN}$ \\
\hline I need more status and respect on my job. & 3.01 & 1.16 & $\mathrm{MeS}$ & $\mathrm{MN}$ \\
\hline I receive an inadequate salary for the work I do. & 3.09 & 1.18 & $\mathrm{MeS}$ & $\mathrm{MN}$ \\
\hline $\begin{array}{c}\text { I lack recognition for the extra work and/or good } \\
\text { teaching I do. }\end{array}$ & 2.82 & 1.17 & $\mathrm{MeS}$ & $\mathrm{MN}$ \\
\hline Overall & $\mathbf{2 . 8 7}$ & $\mathbf{0 . 8 7}$ & MeS & MN \\
\hline
\end{tabular}

$\begin{array}{lll}\text { Mean } & \text { Descriptive Interpretation (DI) } & \text { Level } \\ 4.50-5.00 & \text { Major Strength (MaS) } & \text { Extremely Noticeable (EN) } \\ 3.50-4.49 & \text { Great Strength (GS) } & \text { Very Noticeable (VN) } \\ 2.50-3.49 & \text { Medium Strength (MeS); } & \text { Moderately Noticeable (MN) } \\ 1.50-2.49 & \text { Mild Strength (MiS) } & \text { Barely Noticeable (BN) } \\ 1.00-1.49 & \text { No Strength (NS) } & \text { Not Noticeable (NN) }\end{array}$

As illustrated in Table 6, the respondents reported that they sometimes that they receive an inadequate salary for the work I do (mean $=3.09, \mathrm{SD}=1.18$ ). They also feel that they need more status and respect on my job (mean $=3.01, \mathrm{SD}=$ 1.16). It seems that they lack recognition for the extra work and/or good teaching they do and promotion and/or advancement opportunities are wanting. With a self-reported overall mean score of 2.87 ( $\mathrm{SD}=0.87$ ), the respondents are moderately experiencing professional distress at work.

Table 7 presents the occupational stress level of the respondents in terms of discipline and motivation. 
Table 7. Occupational Stress (OS) level of the respondents in terms of discipline and motivation

\begin{tabular}{|c|c|c|c|c|}
\hline Indicative Statement & Mean & Std. Dev. & DI & Level \\
\hline \multicolumn{5}{|l|}{ I feel frustrated... } \\
\hline because of discipline problems in my classroom. & 2.98 & 1.16 & $\mathrm{MeS}$ & MN \\
\hline having to monitor pupil behavior. & 2.96 & 1.08 & $\mathrm{MeS}$ & $\mathrm{MN}$ \\
\hline because some students would better if they tried. & 3.15 & 1.05 & MeS & $\mathrm{MN}$ \\
\hline attempting to teach students who are poorly motivated. & 3.13 & 1.15 & $\mathrm{MeS}$ & $\mathrm{MN}$ \\
\hline because of inadequate/poorly defined discipline problems. & 3.09 & 1.11 & $\mathrm{MeS}$ & $\mathrm{MN}$ \\
\hline when my authority is rejected by pupils/administration. & 3.04 & 1.09 & $\mathrm{MeS}$ & $\mathrm{MN}$ \\
\hline Overall & 3.06 & 0.90 & MeS & MN \\
\hline
\end{tabular}

$\begin{array}{lll}\text { Mean } & \text { Descriptive Interpretation (DI) } & \text { Level } \\ 4.50-5.00 & \text { Major Strength (MaS) } & \text { Extremely Noticeable (EN) } \\ 3.50-4.49 & \text { Great Strength (GS) } & \text { Very Noticeable (VN) } \\ 2.50-3.49 & \text { Medium Strength (MeS); } & \text { Moderately Noticeable (MN) } \\ 1.50-2.49 & \text { Mild Strength (MiS) } & \text { Barely Noticeable (BN) } \\ 1.00-1.49 & \text { No Strength (NS) } & \text { Not Noticeable (NN) }\end{array}$

As presented in Table 7, the respondents feel frustrated because some students would better if they tried (mean $=3.15$, $\mathrm{SD}=1.05$ ). They are attempting to teach students who are poorly motivated and sometimes feel frustrated because of inadequate/poorly defined discipline problems. They are frustrated when their authority is rejected by pupils/administration. With an overall mean of $3.06(S D=0.90)$, the respondents moderately experience occupational stress in terms of discipline and motivation.

Table 8 shows the occupational stress level of the respondents in terms of emotional manifestations

Table 8. Occupational Stress (OS) level of the respondents in terms of emotional manifestations

\begin{tabular}{|c|c|c|c|c|}
\hline Indicative Statement & Mean & Std. Dev. & DI & Level \\
\hline I respond to stress... & & & & \\
\hline by feeling insecure. & 2.08 & 1.11 & MiS & BN \\
\hline by feeling vulnerable. & 2.37 & 1.13 & MiS & BN \\
\hline by feeling unable to cope. & 2.31 & 1.13 & MiS & BN \\
\hline by feeling depressed. & 2.33 & 1.20 & MiS & BN \\
\hline by feeling anxious. & 2.37 & 1.15 & MiS & BN \\
\hline Overall & $\mathbf{2 . 2 9}$ & $\mathbf{1 . 0 2}$ & MiS & BN \\
\hline
\end{tabular}

$\begin{array}{lll}\text { Mean } & \text { Descriptive Interpretation (DI) } & \text { Level } \\ 4.50-5.00 & \text { Major Strength (MaS) } & \text { Extremely Noticeable (EN) } \\ 3.50-4.49 & \text { Great Strength (GS) } & \text { Very Noticeable (VN) } \\ 2.50-3.49 & \text { Medium Strength (MeS); } & \text { Moderately Noticeable (MN) } \\ 1.50-2.49 & \text { Mild Strength (MiS) } & \text { Barely Noticeable (BN) } \\ 1.00-1.49 & \text { No Strength (NS) } & \text { Not Noticeable (NN) }\end{array}$

As shown in Table 8, it is barely noticeable that the respondents experience emotional manifestations of occupational stress. It indicates that they rarely feel being insecure, vulnerable, unable to cope, depressed, and anxious. With these findings, the respondents still manage to handle situations so they will not be affected by emotional disturbance.

Table 9 describes the occupational stress level of the respondents in terms of fatigue manifestations. 
Table 9. Occupational Stress (OS) level of the respondents in terms of fatigue manifestations

\begin{tabular}{|c|c|c|c|c|}
\hline $\begin{array}{l}\text { Indicative Statement } \\
\text { I respond to stress... }\end{array}$ & Mean & Std. Dev. & DI & Level \\
\hline by sleeping more than usual. & 2.82 & 1.21 & MeS & MN \\
\hline by procrastinating. & 2.48 & 1.05 & MiS & $\mathrm{BN}$ \\
\hline by becoming fatigued in a very short time. & 2.75 & 1.10 & MeS & MN \\
\hline with physical exhaustion. & 2.83 & 1.13 & MeS & MN \\
\hline with physical weakness. & 2.75 & 1.12 & MeS & MN \\
\hline Overall & 2.73 & 0.89 & MeS & MN \\
\hline
\end{tabular}

$\begin{array}{lll}\text { Mean } & \text { Descriptive Interpretation (DI) } & \text { Level } \\ 4.50-5.00 & \text { Major Strength (MaS) } & \text { Extremely Noticeable (EN) } \\ 3.50-4.49 & \text { Great Strength (GS) } & \text { Very Noticeable (VN) } \\ 2.50-3.49 & \text { Medium Strength (MeS); } & \text { Moderately Noticeable (MN) } \\ 1.50-2.49 & \text { Mild Strength (MiS) } & \text { Barely Noticeable (BN) } \\ 1.00-1.49 & \text { No Strength (NS) } & \text { Not Noticeable (NN) }\end{array}$

As described in Table 9, there is a medium strength of fatigue manifestations of occupational stress among the respondents (mean $=2.73, \mathrm{SD}=0.89$ ). It means that they sometimes respond to stress by sleeping more than usual, with physical exhaustion, with physical weakness, and little procrastination.

Table 10 shows the occupational stress level of the respondents in terms of cardiovascular manifestations

Table 10. Occupational Stress (OS) level of the respondents in terms of cardiovascular manifestations

\begin{tabular}{|c|c|c|c|c|}
\hline Indicative Statement & Mean & Std. Dev. & DI & Level \\
\hline I respond to stress... & & & & \\
\hline with feelings of increased blood pressure. & 2.28 & 1.19 & MiS & BN \\
\hline with feeling or heart pounding or racing. & 2.29 & 1.18 & MiS & BN \\
\hline with rapid and/or shallow breath. & 2.42 & 1.23 & MiS & BN \\
\hline Overall & $\mathbf{2 . 3 3}$ & $\mathbf{1 . 1 2}$ & MiS & BN \\
\hline
\end{tabular}

$\begin{array}{lll}\text { Mean } & \text { Descriptive Interpretation (DI) } & \text { Level } \\ 4.50-5.00 & \text { Major Strength (MaS) } & \text { Extremely Noticeable (EN) } \\ 3.50-4.49 & \text { Great Strength (GS) } & \text { Very Noticeable (VN) } \\ 2.50-3.49 & \text { Medium Strength (MeS); } & \text { Moderately Noticeable (MN) } \\ 1.50-2.49 & \text { Mild Strength (MiS) } & \text { Barely Noticeable (BN) } \\ 1.00-1.49 & \text { No Strength (NS) } & \text { Not Noticeable (NN) }\end{array}$

As shown in Table 10, there is a mild strength of cardiovascular manifestations of occupational stress among the respondents (mean $=2.33, \mathrm{SD}=1.12$ ). It directs that they barely respond to stress with rapid and/or shallow breath, feeling or heart pounding or racing, and feeling of increased blood pressure. It is safe to assume that the respondents are not physically bothered by these manifestations of occupational stress.

Table 11 reveals the occupational stress level of the respondents in terms of gastronomical manifestations 
Table 11. Occupational Stress (OS) level of the respondents in terms of gastronomical manifestations

\begin{tabular}{|c|c|c|c|c|}
\hline Indicative Statement & Mean & Std. Dev. & DI & Level \\
\hline I respond to stress... & & & & \\
\hline with stomach pain of extended duration. & 2.47 & 1.24 & MiS & BN \\
\hline with stomach cramps. & 2.50 & 1.17 & MeS & MN \\
\hline with stomach acid. & 2.48 & 1.17 & MiS & BN \\
\hline Overall & $\mathbf{2 . 4 9}$ & $\mathbf{1 . 0 8}$ & MiS & BN \\
\hline
\end{tabular}

$\begin{array}{lll}\text { Mean } & \text { Descriptive Interpretation (DI) } & \text { Level } \\ 4.50-5.00 & \text { Major Strength (MaS) } & \text { Extremely Noticeable (EN) } \\ 3.50-4.49 & \text { Great Strength (GS) } & \text { Very Noticeable (VN) } \\ 2.50-3.49 & \text { Medium Strength (MeS); } & \text { Moderately Noticeable (MN) } \\ 1.50-2.49 & \text { Mild Strength (MiS) } & \text { Barely Noticeable (BN) } \\ 1.00-1.49 & \text { No Strength (NS) } & \text { Not Noticeable (NN) }\end{array}$

As revealed in Table 11, the respondents barely experience gastronomical manifestations of occupational stress at work. It clearly denotes that they rarely respond to stress with stomach cramps, acid, and pain. Most of the time, the respondents are composed enough to hurdle difficult situations. Their health condition is not compromised even they deal with work pressure and challenging tasks.

Table 12 divulges the occupational stress level of the respondents in terms of behavioral manifestations

Table 12. Occupational Stress (OS) level of the respondents in terms of behavioral manifestations

\begin{tabular}{|c|c|c|c|c|}
\hline Indicative Statement & Mean & Std. Dev. & DI & Level \\
\hline I respond to stress... & & & & \\
\hline by using over-the-counter drugs. & 1.71 & 1.09 & MiS & BN \\
\hline by using prescription drugs. & 1.87 & 1.17 & MiS & BN \\
\hline by using alcohol. & 1.48 & 0.96 & MiS & BN \\
\hline by calling in sick. & 1.85 & 1.16 & MiS & BN \\
\hline Overall & $\mathbf{1 . 7 3}$ & $\mathbf{0 . 9 0}$ & MiS & BN \\
\hline
\end{tabular}

$\begin{array}{lll}\text { Mean } & \text { Descriptive Interpretation (DI) } & \text { Level } \\ 4.50-5.00 & \text { Major Strength (MaS) } & \text { Extremely Noticeable (EN) } \\ 3.50-4.49 & \text { Great Strength (GS) } & \text { Very Noticeable (VN) } \\ 2.50-3.49 & \text { Medium Strength (MeS); } & \text { Moderately Noticeable (MN) } \\ 1.50-2.49 & \text { Mild Strength (MiS) } & \text { Barely Noticeable (BN) } \\ 1.00-1.49 & \text { No Strength (NS) } & \text { Not Noticeable (NN) }\end{array}$

As disclosed in Table 12, the respondents least experience behavioral manifestations of occupational stress (mean = $1.73, \mathrm{SD}=0.90$ ). This means that they barely use over-the-counter drugs and alcohol in responding to stress. It means that the respondents are resilient in the adverse effects of occupational stress to their behavior. 
Table 13 discloses the results of test of significant relationship between emotional intelligence and occupational stress dimensions.

As revealed in Table 13, respondent's emotional intelligence and professional investment, emotional manifestations, and fatigue manifestations as dimensions of occupational stress have medium strength of negative association which tend towards practically significant correlation with r-values of $-.442, .417$, and .313 respectively $(\mathrm{p}<.001)$. Meanwhile, teachers' emotional intelligence is statistically and significantly related to discipline and motivation $(\mathrm{r}=-.284, \mathrm{p}<.001)$, professional distress $(\mathrm{r}=-.251, \mathrm{p}<.001)$, behavioral manifestations $(\mathrm{r}=$ $-.251, \mathrm{p}<.001)$, cardiovascular manifestations $(\mathrm{r}=-.229$, $\mathrm{p}$ $<.001)$, gastronomic manifestations $(\mathrm{r}=-.220, \mathrm{p}<.001)$, time management $(\mathrm{r}=-.166, \mathrm{p}<.001)$, and work-related stressors $(\mathrm{r}=-.124, \mathrm{p}<.001)$. It means that respondent's set of emotional and social skills that influence the way they perceive and express themselves, develop and maintain social relationships, cope with challenges, and use emotional information in an effective and meaningful way is inversely proportional to the dimensions of occupational stress such as professional investment, emotional manifestations, discipline and motivation, fatigue manifestations, professional distress, behavioral manifestations, cardiovascular manifestations, gastronomic manifestations, time management and work-related stressors. As the respondents feel positive about themselves, the less occupational stress they experience. Hence, if the teacher wants to be stress-free, they should learn to be emotionally prepared. These findings indicate that teachers adapt to the situations which leads to more satisfaction and less stress.

Table 13. Test of significant relationship between emotional intelligence and occupational stress dimensions

\begin{tabular}{|c|c|c|}
\hline Occupational Stress Dimensions & r-value & $<$ palue \\
\hline Professional Investment & $-.442^{* *}$ & $<.0001$ \\
\hline Time Management & $-.166^{* *}$ & $<.0001$ \\
\hline Work-related Stressors & $-.124^{* *}$ & $<.0001$ \\
\hline Professional Distress & $-.251^{* *}$ & $<.0001$ \\
\hline Discipline and Motivation & $-.284^{* *}$ & $<.0001$ \\
\hline Emotional Manifestations & $-.417^{* *}$ & $<.0001$ \\
\hline Fatigue Manifestations & $-.313^{* *}$ & $<.0001$ \\
\hline Cardiovascular Manifestations & $-.229^{* *}$ & $<.0001$ \\
\hline Gastronomic Manifestations & $-.220^{* *}$ & $<.0001$ \\
\hline Behavioral Manifestations & $-.251^{* *}$ & \\
\hline
\end{tabular}

**Significant at $\mathrm{p}<.01$

Strength of Association

Small

Medium

Large
Coefficient, $r$

Positive Negative

.10 to $.30 \quad-.10$ to -.30

.31 to $.50 \quad-.31$ to -.50

.51 to $1.0 \quad-.51$ to -1.0
Interpretation

Statistically Significant

Towards Practically

Significant Correlation

Practically Significant Correlation 


\section{Conclusions and Recommendations}

Based from the salient findings of the study, the following conclusion was drawn:

There is an inverse and high significant relationship between respondent's emotional intelligence and occupational stress dimensions, hence the null hypothesis is rejected. This means that to overcome stress, teachers should have established a strong emotion and positive mindset.

\section{Recommendations}

Based on the conclusion of the study, the researchers recommend the following:

1. Appropriate and specialized stress management training for teachers early in their career may be designed, taking into account the educational level they will teach in and the relevant job demands.

2. Include communication and counseling skills in their training in order to enhance future supporting working environments.

3. Systematically monitor factors, such as difficult students' situations, in order to design effective interventions.

4. Stress in teaching cannot be eliminated. It could, however, be reduced to manageable levels in order for teachers to be able to function efficiently and maintain mental health and inner harmony.

5. Providing educators with training on how to maintain a balance between work demands and duties, and personal and social-life time, on how to set realistic targets in order to fulfill them, on how to communicate and sustain supportive relations in the workplace, and on how to develop stress-coping strategies, should be foreseen and implemented in undergraduate and postgraduate teachers' studies.

6. Future research may be conducted, assessing various forms of such training, in order to produce evidence-based training interventions, appropriate for educators of each teaching level.

7. Building supportive and helpful relations in the workplace and practicing coping and empowering techniques may help teachers significantly in reducing anxiety and in dealing with occupational stress.

\section{REFERENCES}

[1] Anon. (2019) Occupational Stress. WorkCover State of Queensland. Retrieved from https://www.worksafe.qld.gov .au/laws-and-compliance/workplace-health-and-safety-law s/specific-obligations/health-safety-contact-centres/occupat ional-stress
[2] Cherry, K. (2019). Cross-Sectional Research Method: How Does it Work? Retrieved from: www.verywellmind.com

[3] World Health Organization (2019) Stress at Workplace. Retrieved from https://www.who.int/occupational_health/t opics/stressatwp/en/

[4] Quick, J. C., \& Henderson, D. F. (2016). Occupational Stress: Preventing Suffering, Enhancing Wellbeing. International journal of environmental research and public health, 13(5), 459. doi:10.3390/ijerph13050459

[5] Jain, P. \& Batra, A. (2015) Occupational Stress at Workplace: Study of the Corporate Sector in India. IOSR Journal of Business and Management. E-ISSN: 2278-487X, p-ISSN: 2319-7668. Volume 17, Issue 1.Ver. III (Jan. 2015), PP 13-21. DOI: 10.9790/487X-17131321

[6] Hendres, D. M., Curilaru, V., Arhiri, L., Gherman, M.A. \& Diac, G. (2014) Teachers' Occupational Stress Questionnaire: Psychometric Properties. Rev. Psih., vol. 60, nr. 2, p. 131-140.

[7] Schmutz, Nathan L. (2017) Levels of Teacher Emotional Intelligence in Selected Beat the Odds Schools: A Descriptive Study. Retrieved from https://commons.cu-portland.edu/cgi/viewcontent.cgi?refer er=https://www.google.com/\&httpsredir=1\&article=1023 \&context=edudissertations

[8] Palmer, B.J., Stough, C., Harmer, R. \& Gigna, G (2019), Assessing Emotional Intelligence. The Springer Series on Human Exceptionality, DOI 10.1007/978-0-387-88370-0_ 6 ,

[9] Singh, J.D. (2015) A Study of Emotional Intelligence of teacher Educators in Relation to Certain Demographical Variables. Scholarly Research Journal for Interdisciplinary Studies ISSN 2278-8808. Retrieved from https://www.rese archgate.net/publication/301675452_A_STUDY_OF_EM OTIONAL_INTELLIGENCE_OF_TEACHER_EDUCAT ORS_IN_RELATION_TO_CERTAIN_DEMOGRAPHIC AL_VARIABLES

[10] Tajudin, A. et al (2014) The Effect of Emotional Intelligence and Job Stress on the Teaching Effectiveness among Malaysia Polytechnic Lecturers. International Journal of Sciences: Basic and Applied Research (IJSBAR)(2014) Volume 17, No 1, pp 226-235 